\title{
Diffusion Bonding of Co to TiAu High Temperature Shape Memory Alloy
}

\author{
Yuta Okimori $^{1, *}$, Tomonari Inamura ${ }^{1}$, Hideki Hosoda ${ }^{1}$ and Kenji Wakashima ${ }^{1}$ \\ ${ }^{1}$ Precision and Intelligence Laboratory, Tokyo Institute of Technology, Yokohama 226-8503, Japan
}

\begin{abstract}
We propose a high-temperature actuator composite material composed of a high temperature shape memory alloy (HTSMA) TiAu with a high martensitic transformation temperature $\left(M_{\mathrm{s}}=880 \mathrm{~K}\right)$ and ferromagnetic cobalt with a high Curie temperature $\left(T_{\mathrm{C}}=1388 \mathrm{~K}\right)$. This actuator material can be driven by magnetic field in a bending mode due to ferromagnetic force acting on the Co-layer and generates a large actuation strain which originates from the HTSMA. The purposes of this work are (1) to fabricate the composite materials laminated as TiAu/Co/TiAu by a diffusion bonding method through hot pressing, (2) to characterize the microstructure near the bonding interface between TiAu and Co layers, (3) to evaluate growth behavior of the diffusion layer, and (4) to determine the optimum condition for the fabrication. The composite materials were fabricated by hot pressing at 1073,1173 and $1273 \mathrm{~K}$ for $10 \mathrm{~h}$. The bonding interface between TiAu and Co was observed by a scanning electron microscope and concentration profiles were measured by an energy-dispersive X-ray spectroscopy. In order to evaluate the growth behavior of the diffusion layer, the TiAu/Co composites were aged at 773, 1073, 1173 and $1273 \mathrm{~K}$ for $24 \mathrm{~h}$. It was found that, after the hot pressing, TiAu and Co layers were successfully bonded, and that two reactant intermetallic compounds were formed near the TiAu/Co interface. The intermetallic compounds were identified to be $\mathrm{C} 11_{\mathrm{b}} \mathrm{Ti}(\mathrm{Au}, \mathrm{Co})_{2}$ and $\mathrm{C} 36(\mathrm{Ti}, \mathrm{Au}) \mathrm{Co}_{2}$. As for the growth behavior, the thickness of the diffusion layer was not changed by aging at $773 \mathrm{~K}$. However, the thickness was increased by increasing the aging temperature above $1073 \mathrm{~K}$. The apparent activation energy for the growth of the diffusion layer was estimated to be $280 \pm 20 \mathrm{~kJ} / \mathrm{mol}$ in a temperature range of $1073-1273 \mathrm{~K}$. Using the values of the activation energy and the diffusion constant, the thickness of the diffusion layer was predicted to be sufficiently thin: $12 \mu \mathrm{m}$ by the hot pressing at $1073 \mathrm{~K}$ for $10 \mathrm{~h}$. This predicted value was in good agreement with the experimental result of $7 \mu \mathrm{m}$.

[doi:10.2320/matertrans.MAW200862]
\end{abstract}

(Received May 16, 2008; Accepted July 11, 2008; Published August 13, 2008)

Keywords: diffusion bonding, hot pressing, high temperature shape memory alloy, TiAu, cobalt, actuator material, intermetallic compound, activation energy

\section{Introduction}

Recently, development of high-performance actuator materials which can be used in a high-temperature (HT) environment with actuation strain and frequency in the order of 0.01 and $\mathrm{kHz}$, respectively, is required. ${ }^{1)}$ Shape memory alloys (SMAs) are expected to be power actuator materials because they can generate a large transformation strain about a few percent by thermoelastic martensitic transformation. ${ }^{2)}$ Although several kinds of SMAs such as Ti-Ni, $\mathrm{Cu}$-base, Fe-base, Ti-base SMAs have been known, ${ }^{2)}$ most of practical applications use TiNi. The highest actuation temperature of $\mathrm{TiNi}$ is about $350 \mathrm{~K}^{1,3)}$ and the highest actuation-frequency is limited to be in the order of $100 \mathrm{~Hz}$ in TiNi thin film. ${ }^{4)}$ This is because the actuation of SMAs requires heat dissipation time through heat transfer. Ferromagnetic SMAs (FSMAs) which are driven by an external magnetic field are proposed with a higher frequency of actuation and a larger actuation strain. At present, NiMnGa has been widely studied as FSMA. ${ }^{5)}$ The actuation frequency of $\mathrm{NiMnGa}$ is expected to reach a few $\mathrm{kHz}$ by magnetic field which can be controlled electronically unlike the heatdissipation. There are two actuation principles for FSMAs. One is using the magnetic-induced martensitic transformation whose actuation temperature is higher than martensitic transformation temperature $\left(M_{\mathrm{s}}\right)$. However, it takes a higher external magnetic field for actuation. The other is the reorientation of martensite variants coming from the magnetocrystalline anisotropy of FSMAs which can actuate under relatively low external magnetic field. However, there are some drawbacks in this mode of actuation. One is that the actuation temperature is limited to be lower than both the

*Graduate Student, Tokyo Institute of Technology
$M_{\mathrm{S}}$ and the Curie temperature $\left(T_{\mathrm{C}}\right)$. This is because FSMAs must be in both the martensite state and the ferromagnetic state. The $M_{\mathrm{s}}$ of NiMnGa is, however, decreased with increasing the Curie temperature ${ }^{6)}$ and $M_{\mathrm{S}}$ equals to $T_{\mathrm{C}}$ at around $373 \mathrm{~K}$. ${ }^{6)}$ This means that NiMnGa cannot be used above $373 \mathrm{~K}$ as a FSMA actuator. Another drawback of FSMAs is a relatively low generative force of few $\mathrm{MPa},{ }^{7)}$ which is about $1 / 100$ of that of TiNi.

A few kinds of SMA/ferromagnet composite actuator materials have been already reported. ${ }^{8-10)}$ Taya et al. proposed a new first generation torque actuator based on FSMA composite. ${ }^{8)}$ Unlike the FSMA of NiMnGa which is actuated by homogeneous magnetic field, these SMA/ ferromagnet composites are actuated by magnetic gradient, and have a large actuation strain due to use the SMAs. As discussed previously, the actuation temperature of the SMAs is, however, not too high. Therefore, we propose a new hightemperature magnetostrictive actuator material which is a laminated composite composed of a high temperature SMA (HTSMA) with high $M_{\mathrm{s}}$ and a ferromagnetic material with high $T_{\mathrm{c}}$. The HTSMA/ferromagnet laminated composite has a stacking structure that a thin plate of ferromagnet is sandwiched between relatively thick laminae of HTSMA as HTSMA/ferromagnet/HTSMA. By applying magnetic field with gradient, the ferromagnet layer is elastically bent by magnetic force, and then the reorientation of martensite variants of HTSMA occurs when the magnetic force is sufficiently high. Even though the strain at the surface of the HTSMA lamina reaches a few percent, the strain of the ferromagnet layer can be kept within the elastic region which the value of strain is around $0.2 \%$. The shape strain of the laminated composite is, therefore, perfectly recovered by the inversion of the field or heating above the reverse martensitic transformation temperature $\left(A_{\mathrm{f}}\right)$. 


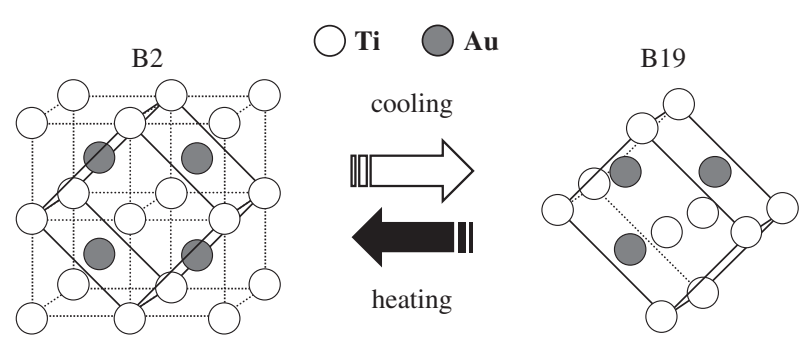

Fig. 1 Unit cells and lattice correspondence of B2 and B19 $\left(a_{\mathrm{B} 19}<b_{\mathrm{B} 19}<c_{\mathrm{B} 19}\right)$.

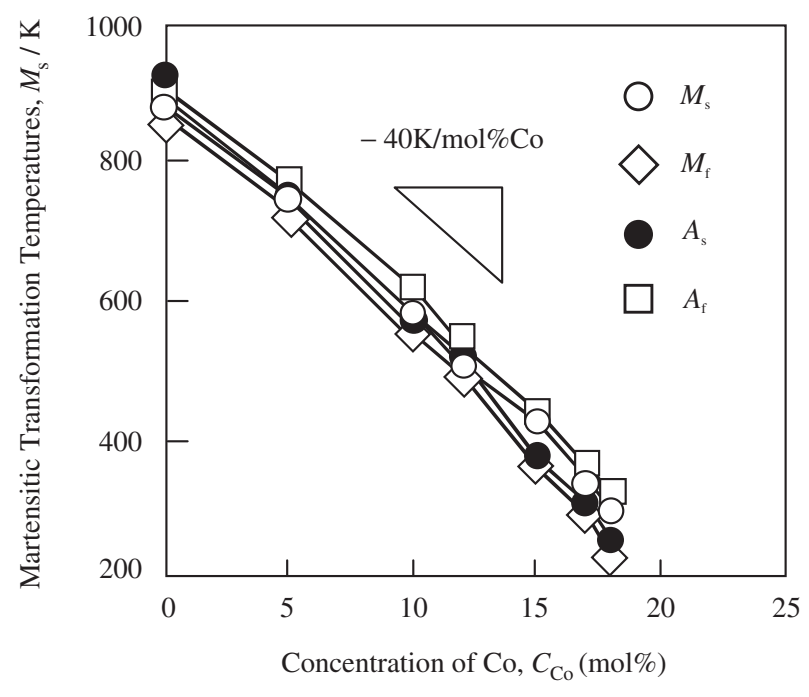

Fig. 2 Martensitic transformation temperatures as a function of $\mathrm{Co}$ concentration. ${ }^{14)}$

In this work, TiAu with $M_{\mathrm{s}}=880 \mathrm{~K}^{11-13)}$ and cobalt $(\mathrm{Co})$ with $T_{\mathrm{C}}=1388 \mathrm{~K}$ were selected as the HTSMA and the ferromagnet, respectively. Figure 1 shows the lattice correspondence and the crystal structures of the B2 parent phase (cubic) and the B19 martensite phase (orthorhombic). Equiatomic TiAu exhibits a thermoelastic martensitic transformation from $\mathrm{B} 2$ to $\mathrm{B} 19$ at around $880 \mathrm{~K}$. The principal strains of the transformation are $-10 \%, 2 \%$ and $7 \%{ }^{14)}$ and the maximum value is close to that of TiNi. ${ }^{15)}$

Diffusion bonding through hot pressing is a conventional technique to fabricate the laminated composite. When Co atoms are solved into TiAu layers, $M_{\mathrm{s}}$ of TiAu is decreased with increasing the amount of Co as seen in Fig. $2 .{ }^{14,16)}$ In addition, there is a possibility that brittle intermetallic compounds are formed as reactants at the interface between TiAu and Co during the hot pressing. In general, such reactants are detrimental for the bonding strength. ${ }^{17)}$ The diffusion behavior near the TiAu/Co interface and the control of the thickness of the diffusion and the reactant layers are, therefore, necessary for the fabrication. Besides, the morphological change near the bonding interface often determines the lifetime, thus, the interfacial change at the operated temperature should be investigated. Therefore, the purposes of this work are (1) to fabricate the composite materials laminated as $\mathrm{TiAu} / \mathrm{Co} / \mathrm{TiAu}$ by a diffusion bonding method through hot pressing, (2) to characterize the microstructure near the bonding interface between TiAu and
Co layers, (3) to evaluate growth behavior of the diffusion and reactant layers, and (4) to determine the optimum condition for the fabrication.

\section{Experimental Procedure}

Starting materials used were elemental Ti, Au and Co with purity of $99.99 \%, 99.99 \%$ and $99.9 \%$, respectively. Equiatomic TiAu ingots were fabricated by Ar arc-melting method with a non-consumable $\mathrm{W}$ electrode and were hot-forged at $1423 \mathrm{~K}$ for $24 \mathrm{~h}$ to be about $0.8 \mathrm{~mm}$ in thickness. Then, the TiAu lamina was cold-rolled with $50 \%$ reduction rate. A Co lamina with the thickness of about $0.4 \mathrm{~mm}$ was cut from a tablet of pure $\mathrm{Co}$, and then cold-rolled with $47 \%$ reduction rate. The final thicknesses of the TiAu and Co lamina were around $0.5 \mathrm{~mm}$ and $0.2 \mathrm{~mm}$, respectively. A Co lamina was sandwiched by two TiAu laminae and they were bonded by hot pressing at 1273,1173 and $1073 \mathrm{~K}$ for $10 \mathrm{~h}$ in vacuum using boron-nitride-coated carbon dices. The heating and cooling rate of the hot pressing was $0.067 \mathrm{~K} \mathrm{~s}^{-1}(4 \mathrm{~K} / \mathrm{min})$. The hot-pressed laminate were cut into some pieces by electro-discharge machining and finished by mechanical polishing. In order to characterize the microstructure and diffusion behavior, cross-section bonding interfaces between TiAu and Co were observed by a field-emission gun type scanning-electron-microscope (FE-SEM). The chemical compositions and concentration profiles near the TiAu/Co interfaces were measured by an energy-dispersive spectroscopy (EDS) analysis equipped with the FE-SEM. In order to evaluate the growth behavior of the diffusion layer, the $\mathrm{TiAu} / \mathrm{Co}$ composites were aged at 773, 1073, 1173 and $1273 \mathrm{~K}$ for $24 \mathrm{~h}$ and then similar observations were made by FE-SEM and EDS.

\section{Results and Discussions}

\subsection{Microstructure and diffusion behavior near the bonding interface between TiAu and Co}

An entire cross-section view of a composite made by hot pressing at $1273 \mathrm{~K}$ for $10 \mathrm{~h}$ is shown in Fig. 3. It is seen that the TiAu and Co layers were uniformly bounded. Figure 4(a) shows a SEM image of the TiAu/Co interface after hot pressing at $1273 \mathrm{~K}$ for $10 \mathrm{~h}$. Figure $4(\mathrm{~b})$ is an enlarged SEM image obtained at a part of "Reactant layer 1" shown in Fig. 4(a). Figure 4(c) is a concentration profile evaluated by EDS analysis corresponding to Fig. 4(a). The points analyzed by EDS are shown in Fig. 4(a). The point of "zero" is the starting point of the EDS analysis. Similarly, Fig. 5(a) and (b) show a cross-section micrograph of the specimen hot pressed at $1173 \mathrm{~K}$ for $10 \mathrm{~h}$ and corresponding concentration profile by EDS, respectively. Hereafter, a "diffusion layer" is defined as the layer in which the Co is solved, and the areas of diffusion layers are shown in Figs. 4(c) and 5(b). It should be noted that "Reactant layer 1" shown in Fig. 4(b) seems to be two phase of bright part and dark part, and chemical compositions of these parts are different each other. The chemical composition of the bright part was 30-32 mol\% Ti, 52-54 mol\% Au and $15-17 \mathrm{~mol} \% \mathrm{Co}$ and insensitive to the distance. Thus, as the concentration profile at "Reactant layer 1 " in Fig. 4(c), the chemical compositions of the bright 


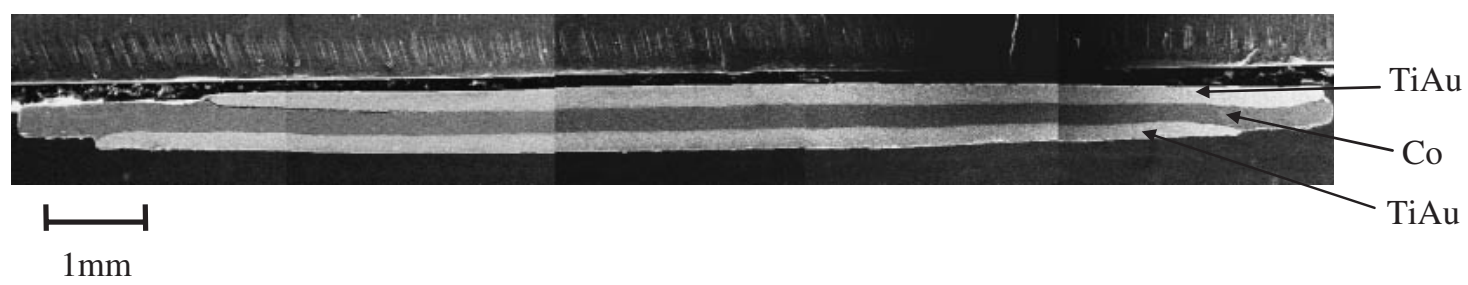

Fig. 3 A cross section SEM image of a composite fabricated at $1273 \mathrm{~K}$ for $10 \mathrm{~h}$.
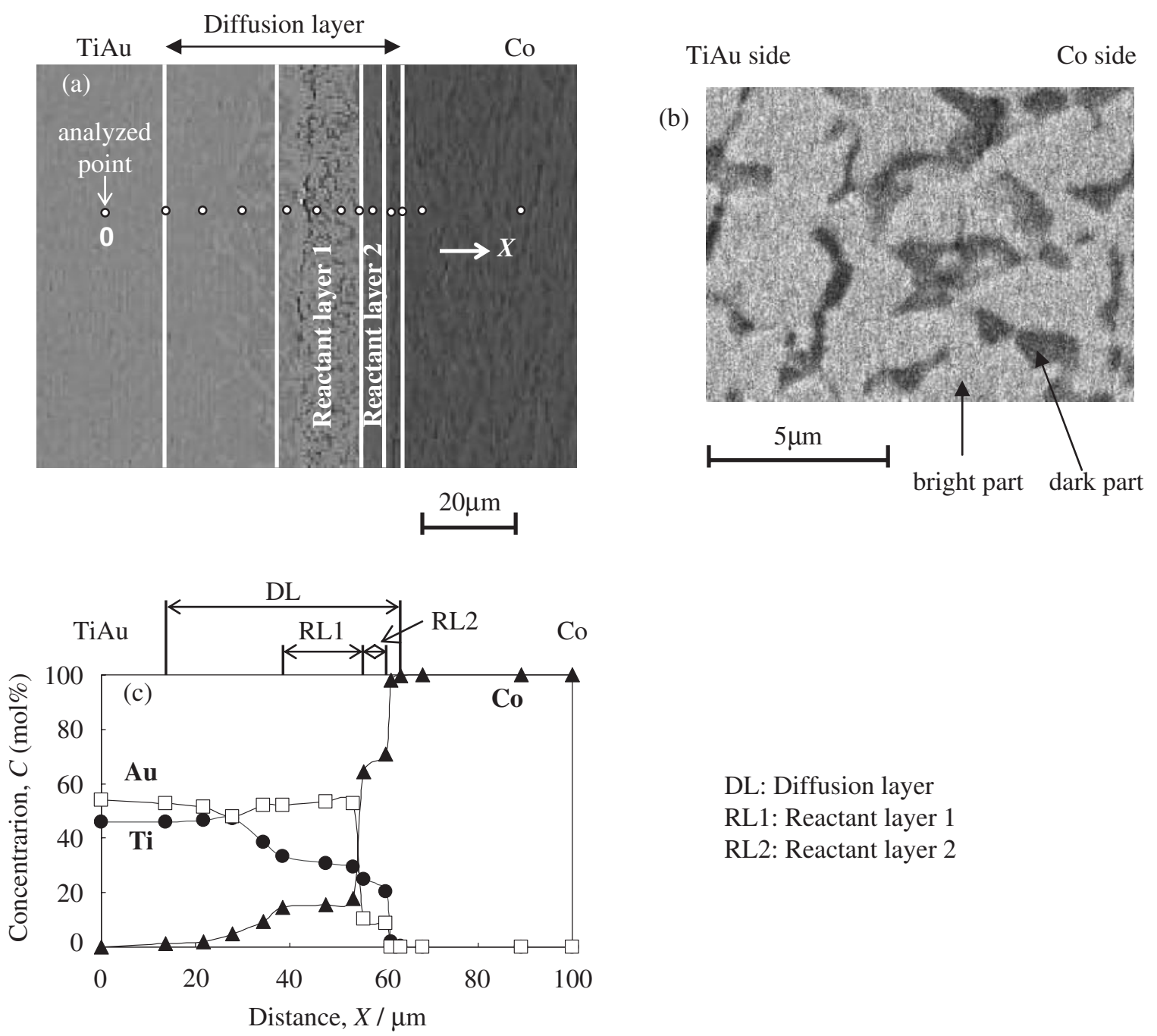

DL: Diffusion layer

RL1: Reactant layer 1

RL2: Reactant layer 2

Fig. 4 (a) A SEM image near the TiAu/Co interface of the specimen fabricated at $1273 \mathrm{~K}$ for $10 \mathrm{~h}$, (b) an magnification Reactant layer 1 obtained at (a), and (c) a concentration profile corresponding to (a).

areas were employed. The composition ratio of $\mathrm{Ti}$ and (Au, Co) was approximately 1:2. On the other hand, "Reactant layer 2" seemed to be single phase. In Figs. 4(c) or 5(b), two-stepwise concentration profiles were obtained as a function of distance. Such stepwise profiles stand for the formation of intermediate phases, and the corresponding layers are called "Reactant layer 1" and "Reactant layer 2", hereafter. The thickness of the diffusion layer and the reactant layers are summarized in Table 1.

In order to identify the intermediate phases formed, the concentration profiles were compared to the Ti-Au-Co ternary phase diagram at $1173 \mathrm{~K}$ in Fig. $6{ }^{18)}$ In the ternary phase equilibrium, some intermetallic phases exist in relatively narrow composition ranges unlike the $\mathrm{B} 2$ phase. Then, Reactant layer 1 is considered to be an intermetallic compound of $(\mathrm{Au}, \mathrm{Co})_{2} \mathrm{Ti}$ with $\mathrm{C} 11_{\mathrm{b}}$ structure. On the other hand, the composition of the dark part of Fig. 4(b) depended on the distance from the point of "zero" as shown in Fig. 4(a). In the dark part, Co-layer side is Co rich (50$60 \mathrm{~mol} \%)$ and the TiAu-layer side is Co poor (20-40 mol\%). It is, therefore, believed that the dark part is a solid solution of B2 $\mathrm{Ti}(\mathrm{Au}, \mathrm{Co})$. As for Reactant layer 2, the composition ratio between $(\mathrm{Ti}, \mathrm{Au})$ and $\mathrm{Co}$ is approximately 1:2 and the composition was insensitive to the distance from the point 

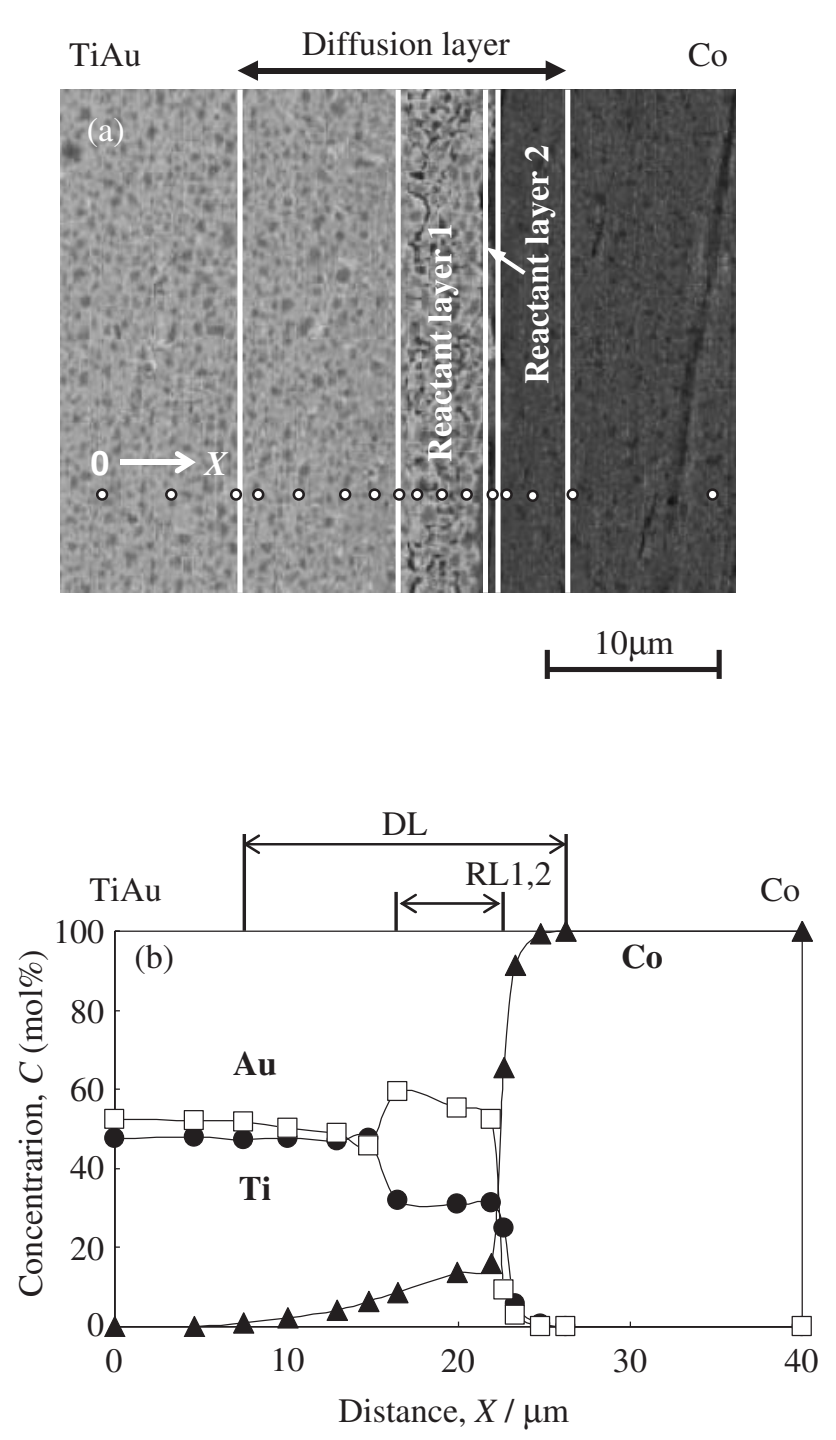

Fig. 5 (a) A SEM image near the TiAu/Co interface of the specimen fabricated at $1173 \mathrm{~K}$ for $10 \mathrm{~h}$, and (b) a concentration profile near the $\mathrm{TiAu} / \mathrm{Co}$ interface corresponding to (a).
Table 1 Thickness of diffusion and reactant layers evaluated by SEMEDS.

\begin{tabular}{cccc}
\hline $\begin{array}{c}\text { Hot-pressing } \\
\text { condition }\end{array}$ & Diffusion layer & Reactant layer 1 & Reactant layer 2 \\
\hline $1273 \mathrm{~K}, 10 \mathrm{~h}$ & $50 \mu \mathrm{m}$ & $15 \mu \mathrm{m}$ & $5 \mu \mathrm{m}$ \\
\hline $1173 \mathrm{~K}, 10 \mathrm{~h}$ & $19 \mu \mathrm{m}$ & $5 \mu \mathrm{m}$ & $\sim 1 \mu \mathrm{m}$ \\
\hline
\end{tabular}

of "zero" as shown in Fig. 4(b). The composition of Reactant layer 2 was 24-26 mol\% Ti, 9-11 mol\%Au and 64-66 mol\%Co. According to the phase diagram, the intermediate phase formed was identified to be $\mathrm{Co}_{2}(\mathrm{Ti}, \mathrm{Au})$ with C36 structure.

The diffusion path deduced from the experimental results and Ti-Au-Co ternary phase diagram is shown in Fig. 7 (indicated by the bold line). When we focus on Co element, Co atoms diffuse from the Co-layer towards TiAu-layer by passing through the $\mathrm{C} 36$ and $\mathrm{C} 11_{\mathrm{b}}$ phases. Thus, the diffusion path near the TiAu/Co interface is $\mathrm{TiAu} / \mathrm{TiAu}(\mathrm{Co}) /$ $(\mathrm{Au}, \mathrm{Co})_{2} \mathrm{Ti} / \mathrm{Co}_{2}(\mathrm{Ti}, \mathrm{Au}) / \mathrm{Co}(\mathrm{Ti}, \mathrm{Au}) / \mathrm{Co}$.

\subsection{The Growth of the diffusion layer}

Intermetallic compounds with complex structures generally brittle, hence, the suppression of formation and growth of the intermetallics is required to prevent the degradation of the bonding strength. In order to evaluate the growth of the diffusion layer, TiAu/Co composites hot pressed at 1173 and $1273 \mathrm{~K}$ for $10 \mathrm{~h}$ were cut into several pieces and they were aged at $773,1073,1173$ and $1273 \mathrm{~K}$ for $24 \mathrm{~h}$. Figure 8 shows SEM images near the TiAu/Co interface of the composite hot pressed at $1173 \mathrm{~K}$ before aging (a), after aging at $773 \mathrm{~K}$ (b), $1073 \mathrm{~K}$ (c), $1173 \mathrm{~K}$ (d) and $1273 \mathrm{~K}$ (e), respectively. Figure 9 shows the concentration profiles corresponding to Fig. 8. Table 2 shows the change in thickness of the diffusion layer due to the aging treatments. By comparing Fig. 8(a) and (b) or Fig. 9(a) and (b), the growth of the diffusion layer was not

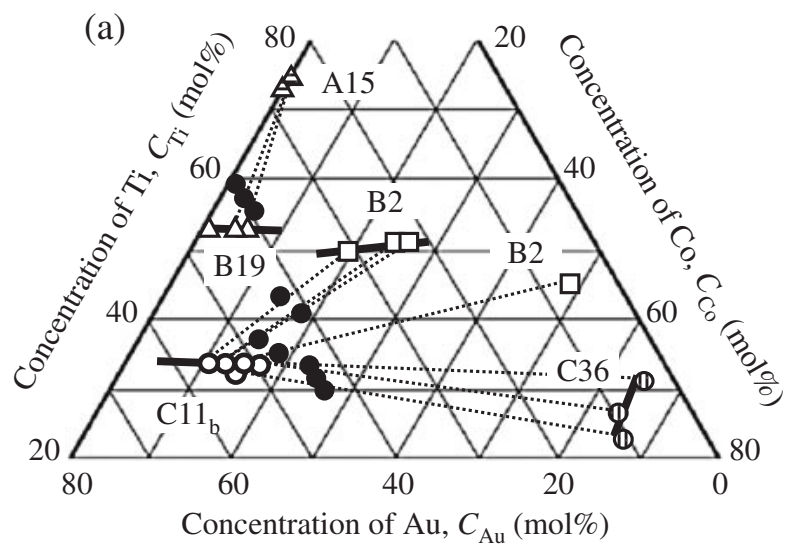

$\begin{array}{ll}\text { Alloys } & \square \text { B2 } \\ \text { O } 111_{\mathrm{b}} & \triangle \mathrm{B} 19 \\ \text { (II) C36 } & \triangle \mathrm{A} 15\end{array}$ (b)

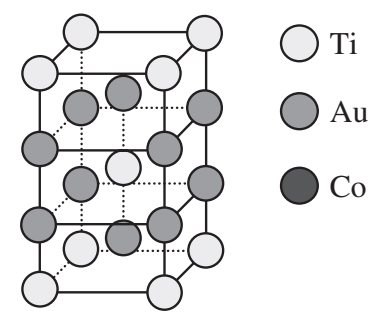

Tetragonal
$\mathbf{C 1 1}_{\mathbf{b}}$
$\mathbf{T i}(\mathbf{A u}, \mathbf{C o})_{2}$

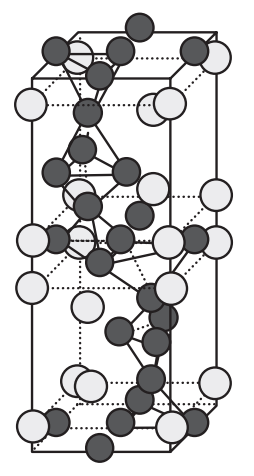

Hexagonal

C36

(Ti,Au)Co $\mathrm{Co}_{2}$

Fig. 6 (a) A portion of the Ti-Au-Co ternary phase diagram at $1173 \mathrm{~K},{ }^{18)}$ and (b) Crystal structures of $\mathrm{C} 11_{\mathrm{b}}$ and $\mathrm{C} 36$ intermetallic compounds. 


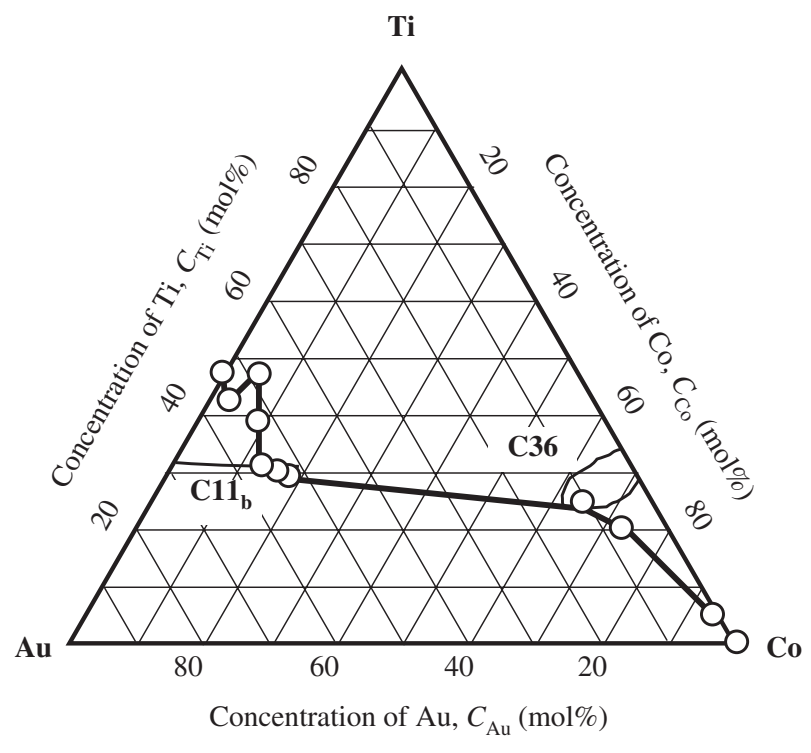

Fig. 7 The diffusion path between TiAu and Co at $1273 \mathrm{~K}$.
Table 2 The change of thickness of diffusion layer by the aging treatments. It is noted that hot pressing was made at $1173 \mathrm{~K}$ for $10 \mathrm{~h}$.

\begin{tabular}{cccccc}
\hline & $\begin{array}{c}\text { Before } \\
\text { aging }\end{array}$ & $\begin{array}{c}773 \mathrm{~K} \\
24 \mathrm{~h}\end{array}$ & $\begin{array}{c}1073 \mathrm{~K} \\
24 \mathrm{~h}\end{array}$ & $\begin{array}{c}1173 \mathrm{~K} \\
24 \mathrm{~h}\end{array}$ & $\begin{array}{c}1273 \mathrm{~K} \\
24 \mathrm{~h}\end{array}$ \\
\hline $\begin{array}{c}\text { Diffusion } \\
\text { layer }\end{array}$ & $19 \mu \mathrm{m}$ & $19 \mu \mathrm{m}$ & $38 \mu \mathrm{m}$ & $109 \mu \mathrm{m}$ & $240 \mu \mathrm{m}$ \\
\hline $\begin{array}{c}\text { Reactant } \\
\text { layer } 1\end{array}$ & $5 \mu \mathrm{m}$ & $5 \mu \mathrm{m}$ & $10 \mu \mathrm{m}$ & $17 \mu \mathrm{m}$ & $37 \mu \mathrm{m}$ \\
\hline $\begin{array}{c}\text { Reactant } \\
\text { layer 2 }\end{array}$ & $\sim 1 \mu \mathrm{m}$ & $\sim 1 \mu \mathrm{m}$ & $2 \mu \mathrm{m}$ & $6 \mu \mathrm{m}$ & $21 \mu \mathrm{m}$ \\
\hline
\end{tabular}

observed when the specimen was aged at $773 \mathrm{~K}$. Then, it is expected that the composite must keep its properties during the service under $773 \mathrm{~K}$ at least for $24 \mathrm{~h}$. However, as seen in Figs. 8 and 9, the thickness of the diffusion layer was increased with further increasing the aging temperature. Similar results were obtained for the composite hot pressed at $1273 \mathrm{~K}$.

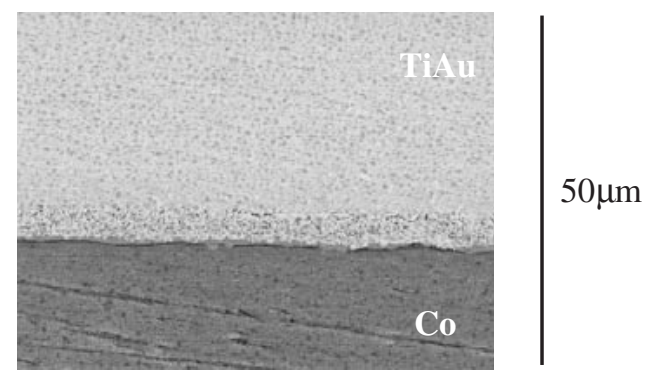

(a) Before aging

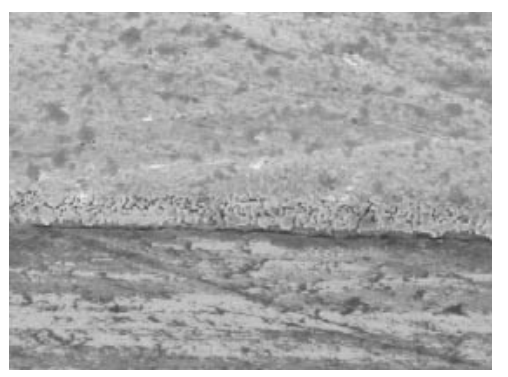

(b) $773 \mathrm{~K}, 24 \mathrm{hrs}$

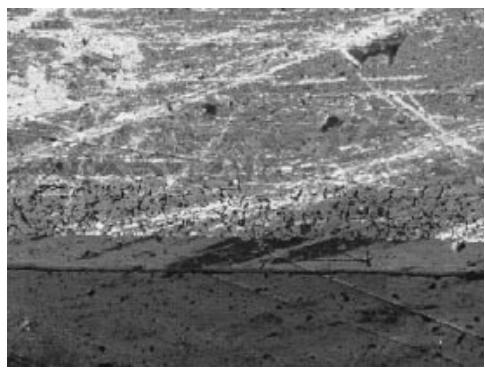

(d) $1173 \mathrm{~K}, 24 \mathrm{hrs}$

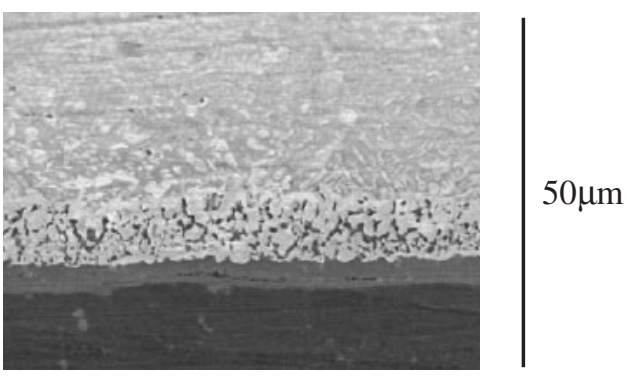

(c) $1073 \mathrm{~K}, 24 \mathrm{hrs}$

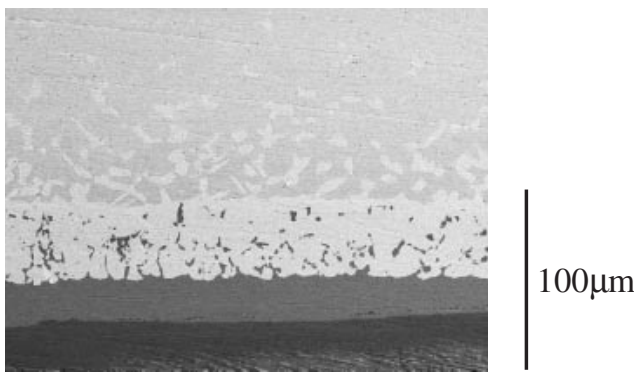

(e) $1273 \mathrm{~K}, 24 \mathrm{hrs}$

Fig. 8 SEM images near the TiAu/Co interface before aging (a), after aging at $773 \mathrm{~K}$ (b), $1073 \mathrm{~K}$ (c), $1173 \mathrm{~K}$ (d) and $1273 \mathrm{~K}$ (e) for $24 \mathrm{~h}$, respectively. 


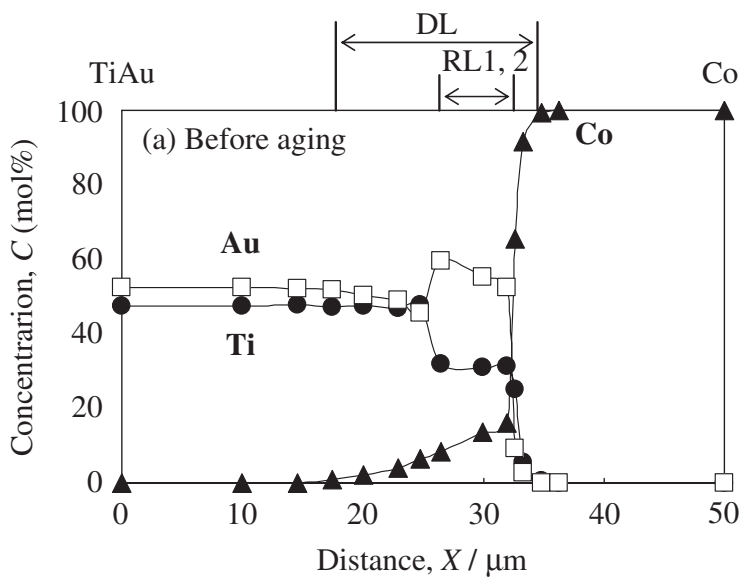

DL: Diffusion layer

RL1: Reactant layer 1

RL2: Reactant layer 2
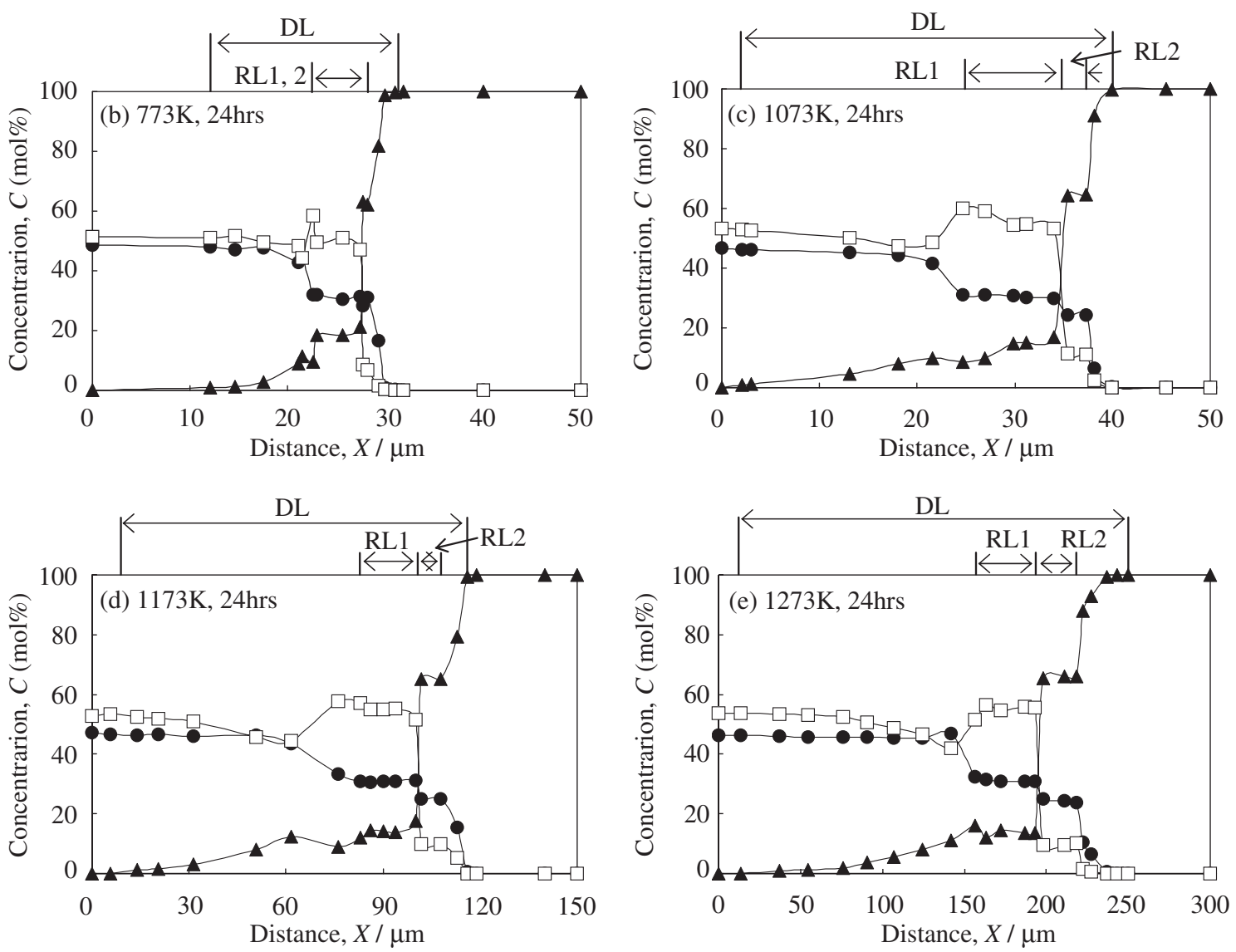

Fig. 9 Concentration profiles near the TiAu/Co interface before aging (a), after aging at $773 \mathrm{~K}$ (b), $1073 \mathrm{~K}$ (c), $1173 \mathrm{~K}$ (d) and $1273 \mathrm{~K}$ (e) for $24 \mathrm{~h}$, respectively.

Based on these results, the growth of the diffusion layers was estimated as follows. The initial position of the TiAu/Co interface was not determined in this study. The width of the diffusion layer, $X$, was used to analyze the kinetics of the growth of the layer. $X$ can be roughly expressed as, ${ }^{19,20)}$

$$
X=\sqrt{2 D t}
$$

where $D$ is the diffusion coefficient and $t$ is the annealing time. The diffusion coefficient $D$ at a temperature $T$ is given as, ${ }^{19,20)}$

$$
D=D_{0} \exp \left(-\frac{Q}{R T}\right)
$$

where $Q$ is the apparent activation energy for the growth of the diffusion layer, $D_{0}$ is the diffusion constant and $R$ is the gas constant. By using the results of the layer growth and eqs. (1) and (2), an Arrhenius plot of $\ln \Delta X$ vs. $1 / T$ was made as shown in Fig. 10. $Q$ and $D_{0}$ were estimated to be $280 \pm 20 \mathrm{~kJ} / \mathrm{mol}$ and $0.58 \pm 0.1 \mathrm{~m}^{2} \mathrm{~s}^{-1}$, respectively.

\subsection{Suppression of the reactant layer}

In order to suppress the brittle failure during actuation, the thicknesses of the reactant layers must be sufficiently thin as well as the diffusion layer. By using the apparent activation energy for the growth of the diffusion layer, we can predict the growth of the diffusion layer. To suppress the reactant 


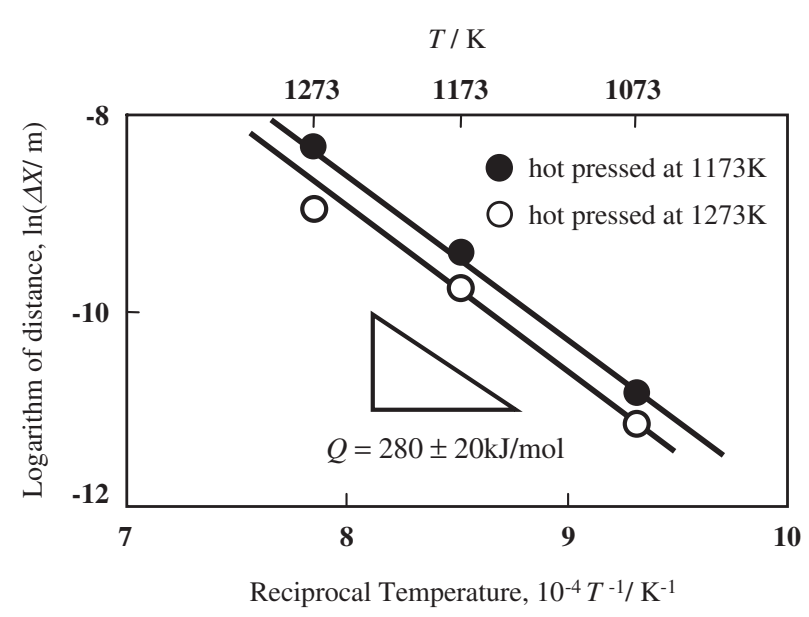

Fig. 10 Arrhenius plot of $\ln \Delta X$ vs. $1 / T$. (a)

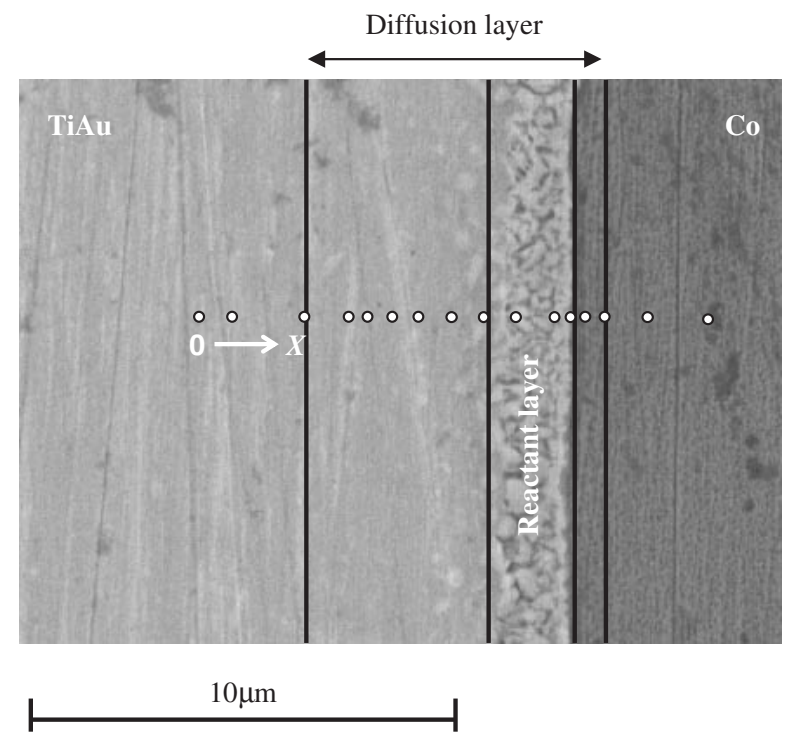

Fig. 11 (a) A SEM image at the interface between TiAu and Co of the specimen fabricated at $1073 \mathrm{~K}$ for $10 \mathrm{~h}$, and (b) a concentration profile corresponding to (a).

layers sufficiently, here, we believe that the thickness of the diffusion layer should be less than $10 \mu \mathrm{m}$. By using the obtained $Q$ and $D_{0}$ and eqs. (1) and (2), an optimum hot pressing condition to make the thickness of the diffusion layer less than $10 \mu \mathrm{m}$ was estimated to be $1073 \mathrm{~K}$ for $10 \mathrm{~h}$. Under the condition, the diffusion layer formed was calculated to be $12 \mu \mathrm{m}$. According to this prediction, a $\mathrm{TiAu} / \mathrm{Co}$ composite was actually made by hot pressing at $1073 \mathrm{~K}$ for $10 \mathrm{~h}$. Figure 11(a) and (b) shows a SEM image and a corresponding concentration profile near the TiAu/Co interface, respectively. As shown in Fig. 11, the thicknesses of the diffusion layer and Reactant layer were around $7 \mu \mathrm{m}$ and $2 \mu \mathrm{m}$, respectively. These values are in good agreement with the prediction, and it is calculated that the thickness of the diffusion layer is suppressed less than $10 \mu \mathrm{m}$ when the composite was hot pressed at $1073 \mathrm{~K}$ for $10 \mathrm{~h}$.

\section{Conclusions}

(1) The thickness of the diffusion layer was increased with increasing the temperature for the hot-pressing: $19 \mu \mathrm{m}$ at $1173 \mathrm{~K}$ and $50 \mu \mathrm{m}$ at $1273 \mathrm{~K}$.

(2) Two intermediate phases were formed near the TiAu/ Co interface, and they were identified to be $\mathrm{C} 11_{\mathrm{b}}$ $\mathrm{Ti}(\mathrm{Au}, \mathrm{Co})_{2}$ and $\mathrm{C} 36(\mathrm{Ti}, \mathrm{Au}) \mathrm{Co}_{2}$. Besides, the diffusion path near the $\mathrm{TiAu} / \mathrm{Co}$ interface is determined as TiAu/ $\mathrm{TiAu}(\mathrm{Co}) /(\mathrm{Au}, \mathrm{Co})_{2} \mathrm{Ti} / \mathrm{Co}_{2}(\mathrm{Ti}, \mathrm{Au}) / \mathrm{Co}(\mathrm{Ti}, \mathrm{Au}) / \mathrm{Co}$.

(3) The growth of the diffusion layer was not observed when aged at $773 \mathrm{~K}$ for $24 \mathrm{~h}$. However, the thickness of the diffusion layer was increased with further increasing the aging temperature.

(4) The kinetics of the growth of the diffusion layer was quantitatively analyzed to control the thickness of the diffusion layer. The apparent activation energy $Q$ and the diffusion constant $D_{0}$ were estimated to be $Q=$ $280 \pm 20 \mathrm{~kJ} / \mathrm{mol}$ and $D_{0}=0.58 \pm 0.1 \mathrm{~m}^{2} \mathrm{~s}^{-1}$, respectively. Based on these values, the optimum hot-pressing condition was determined to be the temperature of $1073 \mathrm{~K}$ and the duration of $10 \mathrm{~h}$. The predicted thickness of diffusion layer $(12 \mu \mathrm{m})$ was in good agreement with the experimental value $(7 \mu \mathrm{m})$.

\section{Acknowledgements}

This work was supported by MEXT Grant-in-Aid for Fundamental Scientific Research on Priority Areas, No. 438 "Next-Generation Actuators Leading Breakthroughs" No. 17040014 (2005-2006) and No. 19016012 (2007-2008).

\section{REFERENCES}

1) G. S. Firstov, J. Van Humbeek and Yu. N. Koval: J. Intell. Mater. Syst. Struct. 17 (2006) 1041-1047.

2) S. Miyazaki and K. Otsuka: ISIJ Intl. 29 (1989) 353-377.

3) W. Tang, B. Sundman, R. Sandstrom and C. Qiu: Acta Mater. 47 (1999) 3457-3468.

4) S. Miyazaki, V. H. No, M. Taniguchi and H. Suzuki: J. Phys. IV 11 (2001) Pr8407.

5) K. Ullakko, J. K. Huang, C. Kantner, R. C. O'Handley and V. V. Kokorin: Appl. Phys. Lett. 69 (1996) 1966-1968.

6) V. A. Chernenko: Scripta Mater. 40 (1999) 523-527.

7) A. Sozinov, A. A. Likhachev and K. Ulakko: IEEE Trans. Magn. 38 (2002) 2814-2816.

8) M. Taya, T. Wada, M. Kusaka and C. C. Lee Ryan: Ind. Commercial Appl. Smart Struct. Technol. 5054 (2003) 156-164.

9) Y. Furuya and T. Okazaki: J. JILM 55 (2005) 233-241. 
10) Z. G. Wei, R. Sandstrom and S. Miyazaki: J. Mater. Sci. 33 (1998) 3763-3783.

11) J. Van Humbeeck and G. Firstov: The forth Pacific Rim International Conference on Advanced Materials and Processing (PRICM4), eds. S. Hanada, Z. Zhong, S. W. Nam and R. N. Wright: 2 (2001) p. 1871.

12) H. C. Donkersloot and J. H. N. Van Vucht: J. Less-Common Met. 20 (1970) 83-91.

13) J. L. Murray: BINARY ALLOY PHASE DIAGRAMS, eds. T. B. Massalski, J. L. Murray, L. H. Bernett and H. Baker: ASM (1986).

14) H. Hosoda, R. Tachi, T. Inamura, K. Wakashima and S. Miyazaki: Mater. Sci. Forum 561 (2007) 1541-1544.

15) S. Miyazaki, S. Kimura, K. Otsuka and Y. Suzuki: Scr. Metall. 18
(1984) 883-888.

16) T. Kawamura, R. Tachi, T. Inamura, H. Hosoda, K. Wakashima, K. Hamada and S. Miyazaki: Mater. Sci. Eng. A 438-440 (2006) 383-386.

17) M. Ghosh, S. Chatterjee and B. Mishra: Mater. Sci. Eng. A 363 (2003) 268-274.

18) Y. Tsugane, T. Inamura, K. Wakashima and H. Hosoda: Advanced Intermetallic-Based Alloys, Materials Research Society Proceedings 980 (2007) pp. II05-52-1.

19) P. G. Shewmon: Diffusion in Solids. Second Edition, (TMS, Warrendale, PA 1989), Chapter 1, pp. 9-51.

20) P. G. Shewmon: Diffusion in Solids. Second Edition, (TMS, Warrendale, PA 1989), Chapter 4, pp. 131-150. 